\title{
Landscape of the regulatory elements for lysine 2-hydroxyisobutyrylation pathway
}

He Huang ${ }^{1, *}$, Zhouqing Luo ${ }^{2,3, *}$, Shankang Qi ${ }^{1, *}$, Jing Huang ${ }^{3, *}$, Peng Xu ${ }^{3}$, Xiuxuan $\mathrm{Wang}^{4}, \mathrm{Li} \mathrm{Gao}^{4}, \mathrm{Fangyi}^{5} i^{5}$, Jian Wang, Wenhui Zhao ${ }^{6}$, Wei Gu ${ }^{7}$, Zhucheng Chen ${ }^{3}$, Lunzhi Dai ${ }^{4}$, Junbiao Dai ${ }^{2,3}$, Yingming Zhao ${ }^{1}$

${ }^{1}$ Ben May Department for Cancer Research, The University of Chicago, Chicago, IL 60637, USA; ${ }^{2}$ Center for Synthetic Biology Engineering Research, Shenzhen Institutes of Advanced Technology, Chinese Academy of Sciences, Shenzhen, Guangdong 518055, China: ${ }^{3}$ MOE Key Laboratory of Bioinformatics and Center for Synthetic and Systems Biology, School of Life Sciences, Tsinghua University, Beijing 100084, China: ${ }^{4}$ Department of General Practice and Lab of PTM, State Key Laboratory of Biotherapy, West China Hospital, Sichuan University, Collaborative Innovation Center of Biotherapy, Chengdu, Sichuan 610041, China; ${ }^{5}$ School of Pharmaceutical Sciences, Tsinghua University, Beijing 100084, China; ${ }^{6}$ Department of Biochemistry and Molecular Biology, Health Science Center and Beijing Key Laboratory of Protein Posttranslational Modifications and Cell Function, Peking University, Beijing 100191, China; ${ }^{7}$ Institute for Cancer Genetics, Department of Pathology and Cell Biology, Herbert Irving Comprehensive Cancer Center, College of Physicians and Surgeons, Columbia University, 1130 Nicholas Avenue, New York, NY 10032, USA

Short-chain fatty acids and their corresponding acyl-CoAs sit at the crossroads of metabolic pathways and play important roles in diverse cellular processes. They are also precursors for protein post-translational lysine acylation modifications. A noteworthy example is the newly identified lysine 2-hydroxyisobutyrylation $\left(K_{\text {hib }}\right)$ that is derived from 2-hydroxyisobutyrate and 2-hydroxyisobutyryl-CoA. Histone $K_{\text {hib }}$ has been shown to be associated with active gene expression in spermatogenic cells. However, the key elements that regulate this post-translational lysine acylation pathway remain unknown. This has hindered characterization of the mechanisms by which this modification exerts its biological functions. Here we show that Esa1p in budding yeast and its homologue Tip60 in human could add $K_{\text {hib }}$ to substrate proteins both in vitro and in vivo. In addition, we have identified HDAC2 and HDAC3 as the major enzymes to remove $K_{\text {hib }}$. Moreover, we report the first global profiling of $K_{\text {hib }}$ proteome in mammalian cells, identifying $6548 \mathrm{~K}_{\text {hib }}$ sites on 1725 substrate proteins. Our study has thus discovered both the "writers" and "erasers" for histone $K_{\text {hib }}$ marks, and major $K_{\text {hib }}$ protein substrates. These results not only illustrate the landscape of this new lysine acylation pathway, but also open new avenues for studying diverse functions of cellular metabolites associated with this pathway.

Keywords: post-translational modification; lysine 2-hydroxyisobutyrylation; regulatory element; acyltransferase; deacylase; substrate

Cell Research (2018) 28:111-125. doi:10.1038/cr.2017.149; published online 1 December 2017

\section{Introduction}

About 17000 cellular metabolites are now annotated in the Kyoto Encyclopedia of Genes and Genomes (KEGG)

*These four authors contributed equally to this work.

Correspondence: Yingming Zhao ${ }^{\mathrm{a}}$, Junbiao Dai ${ }^{\mathrm{b}}$, Lunzhi Dai ${ }^{\mathrm{c}}$

aE-mail: Yingming.Zhao@uchicago.edu

bE-mail: junbiao.dai@siat.ac.cn

${ }^{c}$ E-mail: lunzhi.dai@scu.edu.cn

Received 18 May 2017; revised 2 August 2017; accepted 16 August 2017; published online 1 December 2017 database [1]. Previous studies demonstrated a few major mechanisms by which cellular metabolites exert their functions, such as reversible binding to a protein to activate or inhibit its function, and serving as a precursor for protein post-translational modifications (PTMs) [24]. Nevertheless, the scope and broad functions of most cellular metabolites remain unknown, representing one of major black boxes in modern biology [5]. Short-chain fatty acids are a family of metabolites that are generated by either metabolism of host mammalian cells or microbial fermentation in the gut [6]. Emerging evidence suggests that the microbial-derived metabolites can be either 
harmful or beneficial to human health [7, 8]. They have broad functions in signaling, host metabolism and immunity [9]. Despite much progress, the molecular mechanisms through which these molecules exert their function remain elusive. It was recently shown that short-chain fatty acids could serve as precursors for synthesis of their corresponding acyl-CoAs that in turn regulate histone modifications and gene expression [10]. This result leads to an intriguing hypothesis that metabolites from microbial fermentation can regulate epigenetic programs and control gene expression [11].

2-Hydroxyisobutyrate, a cellular short-chain fatty acid, has been detected at high levels in the urine of obese people and is associated with the presence of some gut microbiota $[12,13]$. The dynamics of symbiotic gut microbiota-associated metabolites, including 2-hydroxyisobutyrate, have been associated with diverse host metabolic phenotypes [13, 14]. Remarkably, 2-hydroxyisobutyrate is a precursor for the synthesis of 2-hydroxyisobutyryl-CoA and moreover, lysine 2-hydroxyisobutyrylation $\left(\mathrm{K}_{\mathrm{hib}}\right)$, a new type of histone PTM [15]. This histone mark poses unique features that differ from the widely studied histone lysine acetylation $\left(\mathrm{K}_{\mathrm{ac}}\right)$ and methylation $\left(\mathrm{K}_{\mathrm{me}}\right)$ marks. It has a unique chemical structure, specific genomic distributions and exhibits varied dynamics among diverse model systems. ChIP-seq, gene expression analysis and immunodetection have indicated that in male germ cells $\mathrm{H} 4 \mathrm{~K} 8_{\text {hib }}$ is associated with regions of active gene transcription, in both meiotic and post-meiotic cells. These lines of evidence suggest that $\mathrm{K}_{\text {hib }}$ is mechanistically and functionally different from histone $\mathrm{K}_{\mathrm{ac}}$ and $\mathrm{K}_{\mathrm{me}}$ [15]. Importantly, we have identified a unique regulatory function of two cellular metabolites, 2-hydroxyisobutyrate and 2-hydroxyisobutyryl-CoA. Nevertheless, the key elements regulating this PTM pathway remain unknown, hindering functional studies of this modification in diverse biological systems and disease settings.

The history of PTM biology clearly shows that exploration of crucial regulatory proteins for a PTM pathway is key for studying its biology. In this respect, $\mathrm{K}_{\mathrm{ac}}$ provides an excellent example. $\mathrm{K}_{\mathrm{ac}}$ was originally discovered in core histones in the 1960s, findings that led to diverse correlative studies between histone $\mathrm{K}_{\mathrm{ac}}$ and chromatin structure and transcriptional activity $[16,17]$. The identification of histone acetyltransferases was a turning point for $\mathrm{K}_{\mathrm{ac}}$ biology $[18,19]$. Demonstration of the involvement of $\mathrm{K}_{\mathrm{ac}}$ in the regulation of p53 function inspired the research community to investigate the regulatory roles of $\mathrm{K}_{\mathrm{ac}}$ in transcription factors [20]. The identification of $\mathrm{K}_{\mathrm{ac}}$ substrates in cytosolic and mitochondrial proteins using proteomic approaches stimulated studies on the non-nuclear functions of this interesting PTM [2124]. Likewise, discovery of the building blocks for the $\mathrm{K}_{\text {hib }}$ pathway will undoubtedly lay a concrete foundation for studying its diverse cellular functions.

In this study, by screening a yeast knock-out (YKO) library and through mutational studies, we found that the Esa1-containing Saccharomyces cerevisiae piccolo NuA4 (picNuA4) histone acetyltransferase complex has $\mathrm{K}_{\text {hib }}$ transferase activity. Esalp's human homolog Tip60, a well-known MYST family acetyltransferase member [25], is also identified as a "writer" able to catalyze $\mathrm{K}_{\text {hib }}$ in mammalian cells both in vitro and in vivo. In addition, we demonstrated that histone deacetylases2 (HDAC2) and HDAC3 in mammalian cells can both serve as "erasers" to remove $\mathrm{K}_{\text {hib }}$ in vitro and in vivo. Moreover, we report the first global identification of $\mathrm{K}_{\text {hib }}$ substrates in human cells. Our screen identified 6548 unique $\mathrm{K}_{\text {hib }}$ sites across 1725 proteins in HeLa cells. Analysis of the substrate proteins reveals that $\mathrm{K}_{\text {hib }}$ is closely associated with the processes of transcription, translation, protein degradation and energy metabolism. Together, our study reveals key building blocks of the $\mathrm{K}_{\text {hib }}$ pathway, and therefore offers a rich source for studying the role of $\mathrm{K}_{\text {hib }}$ in diverse cellular process and disease development.

\section{Results}

\section{Esalp in yeast catalyzes the $K_{\text {hib }}$ modification in vivo and in vitro}

Identification of the regulatory enzymes of histone marks is instrumental in studying their functions. Previous studies suggested that $\mathrm{p} 300$, a member of lysine acetyltransferases (KATs), can have enzymatic activity not only for lysine acetylation but also for lysine propionylation, butyrylation and crotonylation $[10,26]$. We therefore hypothesized that some KATs may also have activity toward $\mathrm{K}_{\text {hib }}$. To test this hypothesis, we took advantage of the haploid YKO collection and performed western blot analysis in each mutant strain in which a non-essential KAT was deleted. We found, unfortunately, that none of these enzymes was required for maintaining the $\mathrm{H} 4 \mathrm{~K} 8_{\text {hib }}$ level (Figure 1A).

In addition to these non-essential KATs, the yeast genome encodes another KAT, Esalp, the catalytic subunit of the nucleosome acetyltransferase of the H4 (NuA4) complex, which is required for cell viability [27]. Esalp associates with Yng2p, Eaf6p and Epllp to form the core machinery termed picNuA4, which is joined by Eaflp and other components to form the large complex [28].

We first tested if Esalp could bind 2-hydroxyisobutyryl-CoA using structural modeling. Recently, we solved the crystal structure of the NuA4 core complex, which 


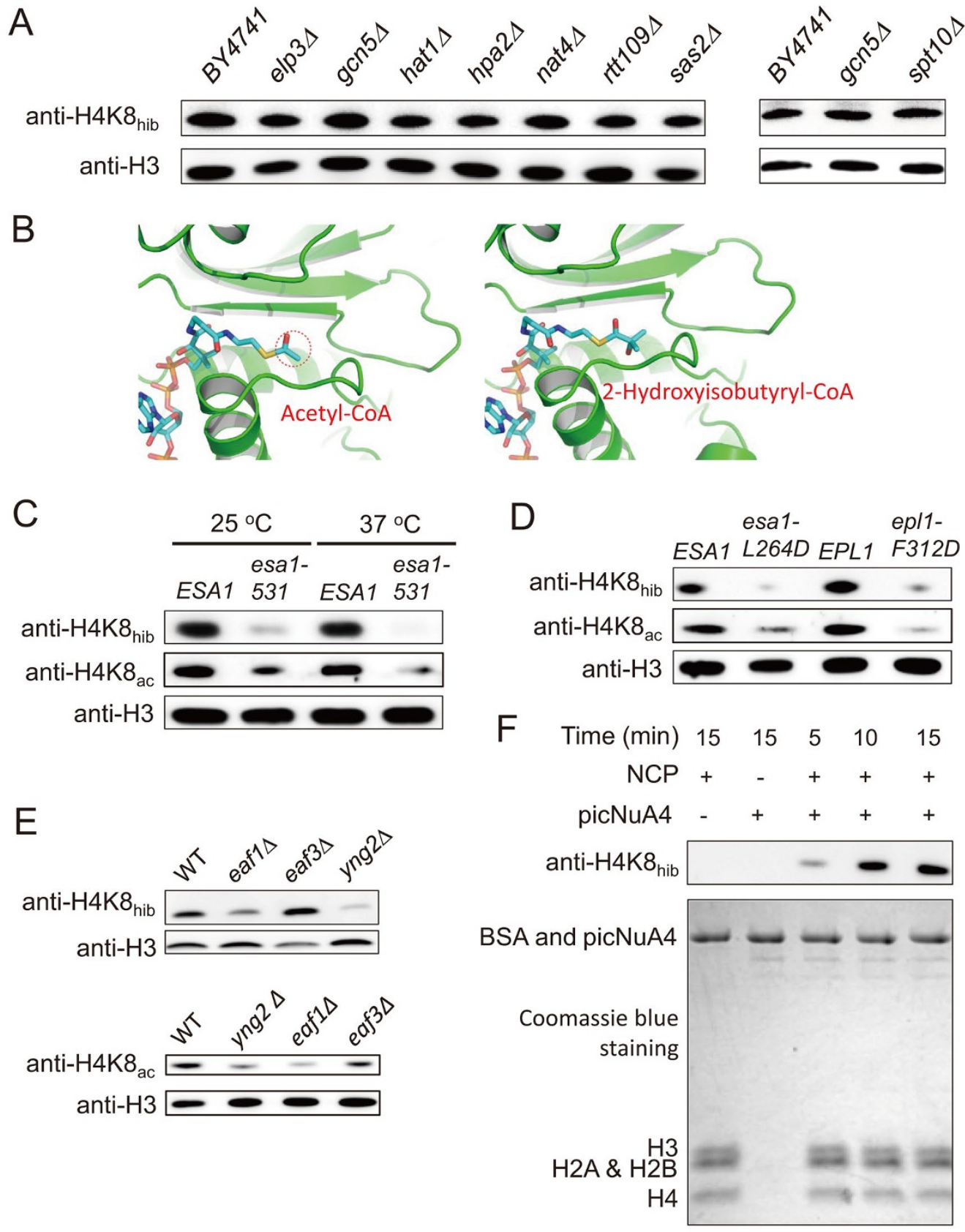

Figure 1 Esa1p in yeast catalyzes $\mathrm{K}_{\text {hib }}$ reaction in vivo and in vitro. (A) $\mathrm{K}_{\text {hib }}$ transferase activity assay of the non-essential KATs from haploid yeast knock-out collection. Cells of different deletion mutants at log phase were harvested and used to detect $\mathrm{H} 4 \mathrm{~K}_{\text {hib }}$ level. (B) Diagram illustrating the catalytic pocket of Esa1p bound with acetyl-CoA (left) and 2-hydroxyisobutyryl-CoA (right). Structures of acetyl-CoA-bound Esa1p (PDB: 5J9W) and 2-hydroxyisobutyryl-CoA (PDB: 4R3U) were used for the modeling. (C) Comparing the levels of $\mathrm{H} 4 \mathrm{~K} 8_{\text {hib }}$ between an ESA1 temperature-sensitive mutant esa1-531 and its wildtype counterpart. esa1-531 decreased $\mathrm{H} 4 \mathrm{~K} 8_{\text {hib }}$ level at both permissive and non-permissive temperature. (D) Mutations in

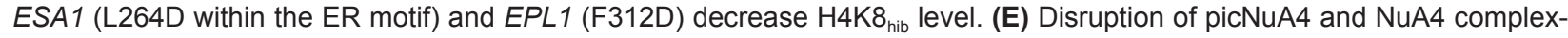
es decreased $\mathrm{H} 4 \mathrm{~K}_{\text {hib }}$ level. (F) PicNuA4 could catalyze the $\mathrm{H} 4 \mathrm{~K} 8_{\text {hib }}$ in vitro. NCP, nucleosome core particle; picNuA4, piccolo NuA4 complex.

revealed a space-sequence double recognition mechanism for targeting the N-terminal tail of histone H4 [29].
When we examined the structure of the catalytic pocket of Esalp bound to acetyl-CoA (PDB 5J9W), we found 
that the catalytic pocket of Esalp is large enough to accommodate other alkylated-CoAs with bigger acyl tails (Figure 1B). To test if 2-hydroxyisobutyryl-CoA would fit into the catalytic pocket of Esalp, we modeled an Esa1p/2-hydroxyisobutyryl-CoA structure based on the structure of acetyl-CoA-bound Esa1p (PDB 5J9W) with the terminal acetyl group replaced with a 2-hydroxyisobutyryl group (from PDB 4R3U). As anticipated, the manner in which 2-hydroxyisobutyryl-CoA can bind to Esa1p is similar to that seen for the acetyl-CoA/Esa1p complex and allows a good fit of the 2-hydroxyisobutyryl group into the catalytic pocket (Figure 1B). Therefore, it is possible that multiple acylations, including $\mathrm{K}_{\text {hib }}$, could be catalyzed by the same enzyme.

We then carried out a series of experiments to test whether Esalp could catalyze $\mathrm{H} 4 \mathrm{~K} 8_{\text {hib }}$ acylation in vivo. First, we compared the levels of $\mathrm{H} 4 \mathrm{~K} 8_{\text {hib }}$ between an ESA1 temperature-sensitive mutant esal-531 and its wild-type counterpart. We found that $\mathrm{H} 4 \mathrm{~K} 8_{\text {hib }}$ persisted in the mutant at permissive temperature $\left(25^{\circ} \mathrm{C}\right)$, despite the reduced level of modification compared to the wild type. In contrast, at the non-permissive temperature $\left(37^{\circ} \mathrm{C}\right)$, the modification was completely abolished (Figure 1C). Second, we constructed a strain carrying an amino-acid substitution (L264D) within the ER motif to diminish the enzymatic activity of Esalp [29]. As shown in Figure $1 \mathrm{D}, \mathrm{H} 4 \mathrm{~K} 8_{\text {hib }}$ was dramatically decreased in this mutant. Therefore, a functional Esalp is required for $\mathrm{H} 4 \mathrm{~K} 8_{\text {hib }}$. Third, we asked if Esa1p-mediated $\mathrm{H} 4 \mathrm{~K} 8_{\text {hib }}$ requires the intact picNuA4 complex, as known for acetylation. We then performed western blot analysis in two strains: one carrying a point mutation in Epllp, F312D, which disrupts its interaction with Esalp; and the other with a deletion of $Y N G 2$. We found the amount of $\mathrm{H} 4 \mathrm{~K} 8_{\text {hib }}$ was drastically decreased in both strains (Figure 1D and 1E). Finally, we tested if the NuA4 complex is also required for $\mathrm{H} 4 \mathrm{~K} 8_{\text {hib }}$ by knocking out $E A F 1$, which maintains the picNuA4 complex but disrupts NuA4 complex [30], or $E A F 3$, another component of the NuA4 complex. The $E A F 1$ deletion strain showed moderate effect on $\mathrm{H} 4 \mathrm{~K} 8_{\text {hib }}$ whereas the EAF3 deletion strain did not (Figure 1E). Taken together, these results indicate that the picNuA4 complex is responsible for histone $\mathrm{H} 4 \mathrm{~K} 8_{\text {hib }}$ in $S$. cerevisiae.

In order to demonstrate that Esalp catalyzes $\mathrm{H} 4 \mathrm{~K} 8_{\text {hib }}$ directly, we performed an in vitro assay using the purified picNuA4 complex and nucleosome core particles (NCPs) [29]. The 2-hydroxyisobutyryl-CoA was synthesized chemically (Supplementary information, Figure S1) and supplied as the donor. The reaction was carried out at room temperature and the production of $\mathrm{H} 4 \mathrm{~K} 8_{\text {hib }}$ was visualized by western blot. We found that picNuA4 can efficiently catalyze 2-hydroxyisobutyrylation on
H4K8 in vitro (Figure 1F). Together, the results of these experiments carried out both in vivo and in vitro demonstrate that Esa1p is the "writer" of $\mathrm{H} 4 \mathrm{~K} 8_{\text {hib }}$ in yeast. Given the broad acetylation substrate spectrum of Esalp [31], H4K8 may serve one of the histone $\mathrm{K}_{\text {hib }}$ substrate sites for Esa1p.

\section{Tip60 has $K_{\text {hib }}$ transferase activity in vitro and in vivo}

Given the $K_{\text {hib }}$ transferase activity of Esalp in yeast, we next hypothesized that Tip60, the human homolog of Esalp, might also be able to catalyze the $\mathrm{K}_{\text {hib }}$ reaction. To test this hypothesis, we first carried out $\mathrm{K}_{\text {hib }}$ reactions in vitro using recombinant histone $\mathrm{H} 4$ protein and 2-hydroxyisobutyryl-CoA as substrate and cofactor, respectively. Acetyl-CoA was used as a positive control for the reactions. Western blot results showed that Tip60 could increase the global level of the histone $\mathrm{H}_{4} \mathrm{~K}_{\text {hib }}$ modification (Figure 2A), although it had a lower intrinsic preference toward the 2-hydroxyisobutyryl-CoA (Supplementary information, Figure S2). Mass spectrometry analysis identified H4K8, H4K12, H4K16 and H4K31 as $\mathrm{K}_{\text {hib }}$ substrates of Tip60 (Supplementary information, Figure $\mathrm{S} 3$ ), indicating that Tip60 is a potential mammalian $\mathrm{K}_{\text {hib }}$ transferase in vitro. To confirm this result, a Tip60-specific inhibitor, TH1834 [32], was used to determine whether it could prevent $\mathrm{H} 4$ from undergoing 2-hydroxyisobutyrylation. Upon treatment of TH1834, the $\mathrm{K}_{\text {hib }}$ level was significantly decreased in a similar fashion as $\mathrm{K}_{\mathrm{ac}}$ (Figure 2B), further suggesting that Tip60 has $\mathrm{K}_{\text {hib }}$ transferase activity in vitro.

We next examined whether Tip60 regulates $\mathrm{K}_{\text {hib }}$ in vivo. Knockdown of Tip60 by short interfering RNA reduced the global levels of $\mathrm{K}_{\text {hib }}$ and $\mathrm{K}_{\mathrm{ac}}$ on histones, while the $\mathrm{K}_{\text {hib }}$ level on a specific residue, $\mathrm{H} 4 \mathrm{~K} 8$, was decreased slightly (Figure 2C). In support of this observation, we found that treatment of cells with the Tip60 inhibitor, TH1834, clearly decreased H4K $8_{\text {hib }}$ signals (Figure 2D). By contrast, overexpression of full-length Tip60 by transient transfection increased both global histone $\mathrm{K}_{\text {hib }}$ and $\mathrm{H} 4 \mathrm{~K} 8_{\text {hib }}$ levels and enhanced the $\mathrm{K}_{\mathrm{ac}}$ positive control as expected (Figure 2E). Quantitative mass spectrometry showed that the levels of histone $\mathrm{H} 4 \mathrm{~K} 8_{\text {hib }}, \mathrm{H} 4 \mathrm{~K} 12_{\text {hib }}$ and $\mathrm{H} 4 \mathrm{~K} 16_{\text {hib }}$ were increased $35 \%-46 \%$ in response to overexpression of Tip60, indicating that these sites are Tip60-targeted $\mathrm{K}_{\text {hib }}$ substrates (Supplementary information, Figure S4).

Taken together, these results demonstrate that Tip60 can regulate $\mathrm{K}_{\text {hib }}$ both in vitro and in vivo.

$H D A C 2$ and $H D A C 3$ are $K_{\text {hib }}$ deacylases in vitro and in vivo

HDACs, which are also called lysine deacetylases 
A

B

C
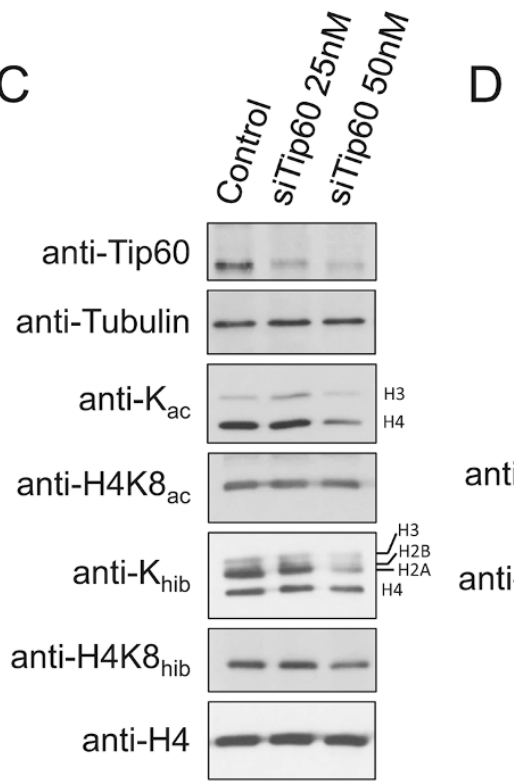
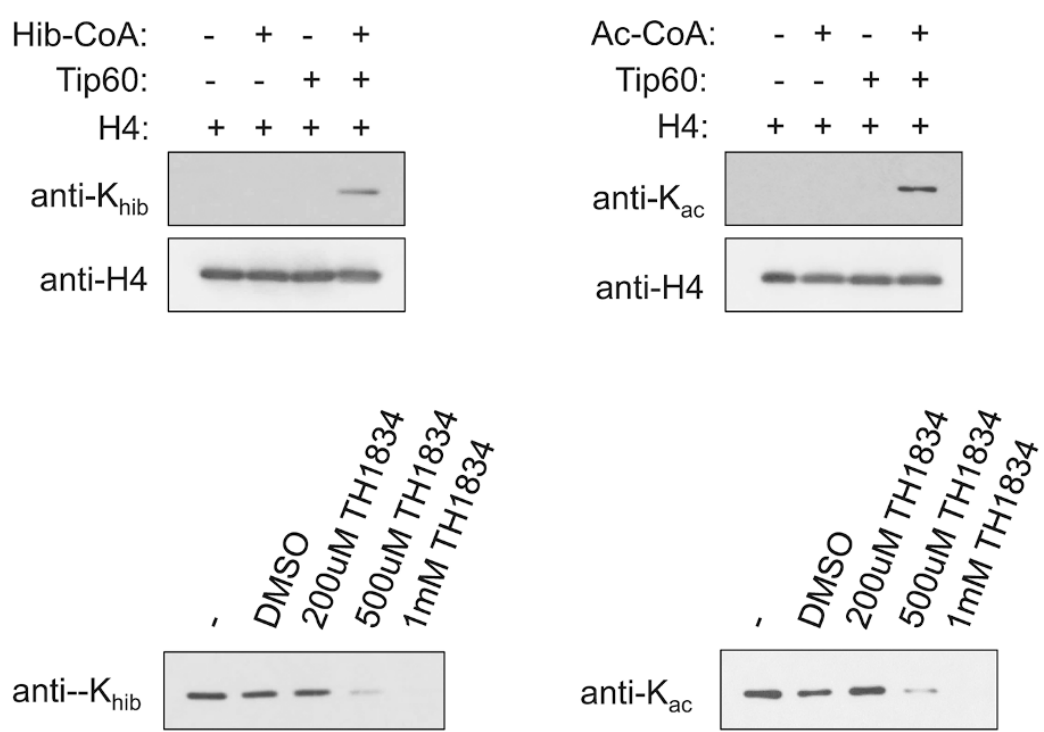

anti-K

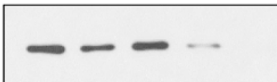

anti-H4

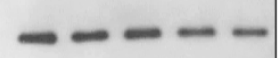

Figure 2 Tip60 has lysine 2-hydroxyisobutyryltrasferase activity in vitro and in vivo. (A) In vitro assay showing $\mathrm{K}_{\text {hib }}$ transferase activity of Tip60. $\mathrm{K}_{\text {hib }}$ or $\mathrm{K}_{\mathrm{ac}}$ activities of recombinant Tip60 were assayed using recombinant $\mathrm{H} 4$ as substrate. Reaction products were detected by western blot with indicated antibodies. (B) TH1834, a Tip60 inhibitor, inhibits Tip60 activity in vitro. $\mathrm{K}_{\text {nib }}$ or $\mathrm{K}_{\mathrm{ac}}$ activities of recombinant Tip60 were assayed using recombinant $\mathrm{H} 4$ as substrate. TH1834 at $200 \mu \mathrm{M}, 500 \mu \mathrm{M}$ and $1 \mathrm{mM}$ was added to the assay. Reaction products were detected by western blot with indicated antibodies. (C) Western blot analysis showing that Tip60 knockdown impairs histone $\mathrm{K}_{\text {hib }}$ in vivo. HeLa cells were treated with siRNAs against Tip60 for $48 \mathrm{~h}$ before being subjected to western blot analysis. The efficiency of siRNA knockdown was verified by western blot. (D) TH1834 inhibits Tip60 activity in vivo. HeLa cells were treated with $200 \mu \mathrm{M}$ of TH1834 for $1 \mathrm{~h}$ or $2 \mathrm{~h}$. Levels of $\mathrm{H} 4 \mathrm{~K} 8_{\mathrm{ac}}$ and $\mathrm{H} 4 \mathrm{~K} 8_{\text {hib }}$ were detected by western blot and $\mathrm{H} 4$ served as loading control. (E) Western blot analysis showing that overexpression of Tip60 increases histone $\mathrm{K}_{\text {hib }}$ in vivo. Flag-Tip60 was transfected into HEK293 cells for $48 \mathrm{~h}$ before being subjected to western blot analysis. 
(KDACs), are a family of enzymes that can remove acetyl groups from the amine at the epsilon position of lysine side chain. Given the fact that some HDACs, such as Sirt5 and Sirt6, can also catalyze removal of other forms of lysine acylation [33-35], we hypothesized that some HDAC member might also have enzymatic activity toward $\mathrm{K}_{\text {hib }}$. To test this possibility, we first carried out an in vitro screen of the 11 class I, II and IV deacetylases (HDAC1-HDAC11) using core histones as the substrates (Figure 3A). This revealed that HDAC2 and HDAC3 have the highest activity for de-2-hydroxyisobutyrylation, whereas HDAC1 only showed marginal activity in vitro. The in vitro de-2-hydroxyisobutyrylation activity of HDAC3 could be further confirmed by the inhibition of $\mathrm{NaBu}$ and TSA; two inhibitors for class I and II HDACs, but not NAM, an inhibitor for class III HDAC [15]. Together, these data suggested that HDAC2 and HDAC3 could remove $\mathrm{K}_{\text {hib }}$ in vitro.

Next, we sought to determine whether HDACs 1-3 could remove $\mathrm{K}_{\text {hib }}$ in vivo. Consistent with the in vitro assay, knockdown and overexpression of HDAC1 slightly affected the global level of histone $\mathrm{K}_{\text {hib }}$ (Figure 3B and 3C), while knockdown of HDAC3 or knockout of HDAC2 increased the global level of histone $\mathrm{K}_{\text {hib }}$ more obviously (Figure 3D and 3E). Compared with HDAC2 knockout, the double depletion of HDAC2 and HDAC3 led to a similar increase of the global histone $\mathrm{K}_{\text {hib }}$ level. In contrast, overexpression of HDAC2 or HDAC 3 reduced the global level of histone $\mathrm{K}_{\text {hib }}$ (Figure 3F). SILAC quantification of the histone $\mathrm{K}_{\text {hib }}$ dynamics indicated that the levels of $K_{\text {hib }}$ decreased by $30 \%$ or more after HDAC 3 overexpression (Supplementary information, Table S1). Moreover, overexpression of both HDAC2 and HDAC3 enhanced such a decrease.

Together, these data support the conclusion that HDAC2 and HDAC3 are $\mathrm{K}_{\text {hib }}$ deacylases both in vitro and in vivo.

\section{Proteomics screening of $K_{\text {hib }}$ peptides in HeLa cells}

To globally identify $\mathrm{K}_{\text {hib }}$ substrate proteins and their modification sites, we carried out proteomic screening in HeLa cells involving peptide fractionation, affinity enrichment of $\mathrm{K}_{\text {hib }}$-peptides and HPLC-MS/MS analysis (Figure 4A). The specificity of the pan anti- $\mathrm{K}_{\text {hib }}$ antibody used for immunoaffinity purification was verified with a dot blot assay; the antibody could only detect the peptide library bearing a fixed 2-hydroxyisobutyrylated lysine but not the peptide library bearing a fixed unmodified lysine, acetylation lysine, butyrylated lysine, crotonylated lysine or $\beta$-hydroxybutyrylated lysine (Supplementary information, Figure S5). The acquired raw MS data were analyzed by Maxquant software with a false discovery rate of $<1 \%$ at protein, peptide and site levels. We further removed those hits with Andromeda scores lower than 40. The experiments were performed as biological triplicates. Using this procedure, we identified $7937 \mathrm{~K}_{\text {hib }}$ sites on 1901 proteins. To improve the reliability of the identified peptides, we eliminated $1213 \mathrm{~K}_{\mathrm{hib}}$ sites with localization probability scores $<0.75$, and eliminated redundant sites. Using these criteria, we identified 6548 unique $\mathrm{K}_{\text {hib }}$ sites on 1725 proteins in triplicate analysis (Supplementary information, Data S1A). Of the 6548 sites, 74\% (4 867) were identified in at least two biological replicates (Figure 4B; Supplementary information, Data S1B), demonstrating the high reproducibility of our procedure. These $\mathrm{K}_{\text {hib }}$ sites were used as high-confidence data set in subsequent analysis.

\section{Sequence preference and subcellular localization of the $K_{\text {hib }}$ proteome}

The identified $\mathrm{K}_{\text {hib }}$ substrates have varied numbers of modification sites. We found that 617 proteins were modified at only one $\mathrm{K}_{\text {hib }}$ site, while 80 proteins had more than $10 \mathrm{~K}_{\text {hib }}$ sites, including Plectin (PLEC) with 58 sites and Myosin-9 (MYH9) with 44 sites (Figure 4C; Supplementary information, Data S1B). To determine whether there are common sequence motifs in $\mathrm{K}_{\text {hib }}$ peptides, we aligned the amino-acid sequences surrounding $\mathrm{K}_{\text {hib }}$ sites against all human background sequences. We found that the negatively-charged amino acids (aspartic acid and glutamic acid) were enriched at both -1 and +1 positions, whereas the positively-charged amino acid lysine was enriched at $-6,-5,+5$ and +6 positions (Figure $5 \mathrm{~A})$. In addition, arginine and lysine residues were under-represented at the -1 and +1 positions, respectively (Figure 5A). Interestingly, proline was largely depleted at most of the positions, making the sites distinct from the reported flanking sequence preference studies of $\mathrm{K}_{\mathrm{ac}}$, lysine malonylation $\left(\mathrm{K}_{\text {mal }}\right)$ and lysine succinylation $\left(\mathrm{K}_{\text {succ }}\right)$ (Figure 5A) [36-39].

To explore the subcellular distribution of $\mathrm{K}_{\text {hib }}$ substrates in cells, we performed a cellular compartment analysis of the $\mathrm{K}_{\text {hib }}$ proteome. Recently, some PTMs, such as $\mathrm{K}_{\text {mal }}$ and $\mathrm{K}_{\text {succ }}$, were reported being significantly enriched in mitochondria [37, 40]. In contrast, only $\sim 15 \%$ of $\mathrm{K}_{\text {hib }}$ proteins were annotated in mitochondria, whereas $61 \%$ and $86 \%$ of $\mathrm{K}_{\text {hib }}$ proteins localized exclusively or partially in nucleus and cytosol, respectively (Figure 5B). This suggests that the $\mathrm{K}_{\text {hib }}$ modification has a very different regulatory mechanism from $\mathrm{K}_{\text {mal }}$ and $\mathrm{K}_{\text {succ }}$. In contrast to $\mathrm{K}_{\mathrm{mal}}$ and $\mathrm{K}_{\text {succ }}$, the subcellular distribution of $\mathrm{K}_{\mathrm{ac}}$ substrates is similar to that of $K_{\text {hib }}$ substrates. The majority of $\mathrm{K}_{\mathrm{ac}}$ substrates often reside in either the cytoplasm or the nucleus, while mitochondria account for $\sim 5 \%$ or less 
A
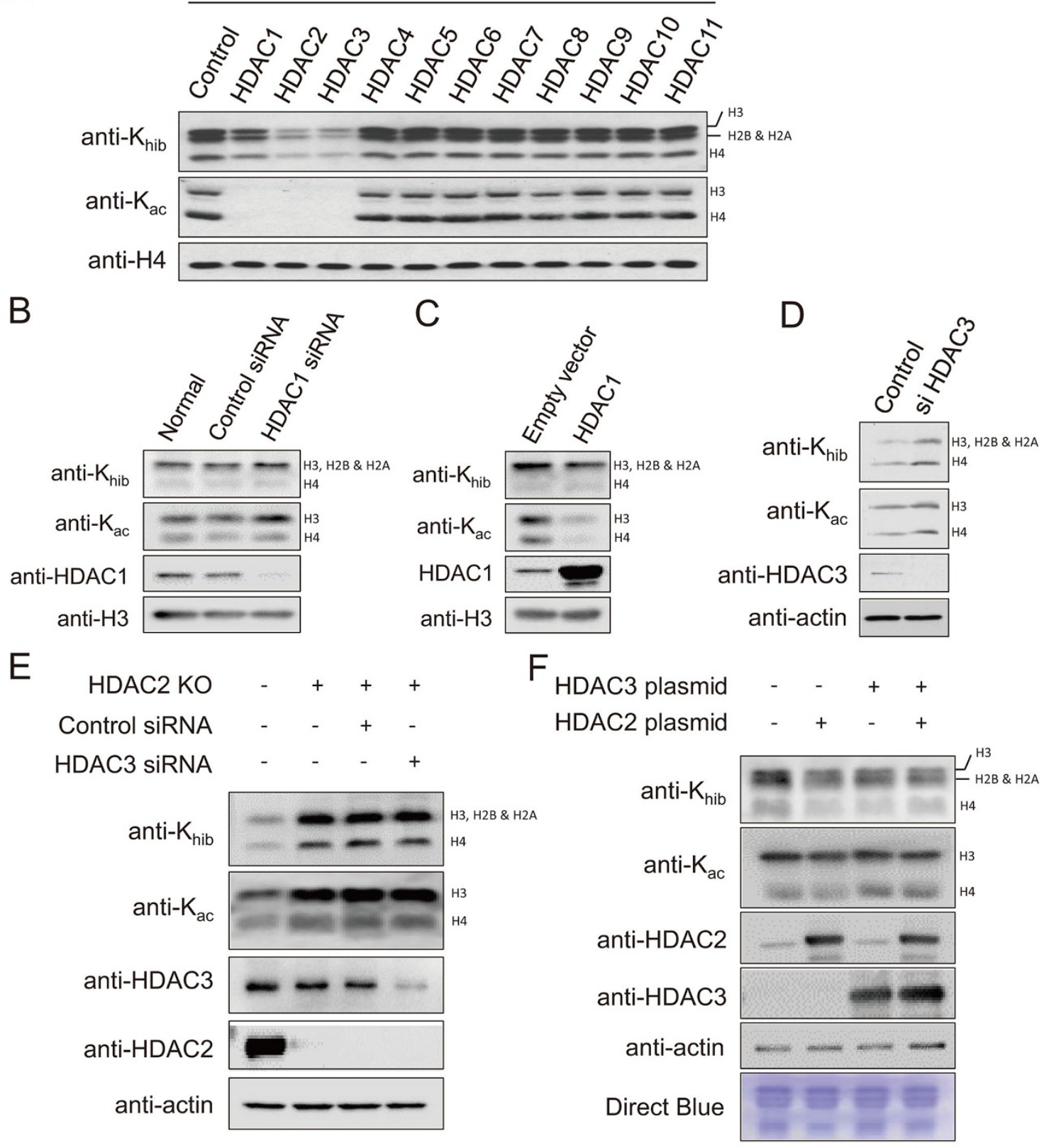

Figure 3 HDAC2 and HDAC3 are $\mathrm{K}_{\text {hib }}$ deacylases in vitro and in vivo. (A) In vitro screen of HDACs' $\mathrm{K}_{\text {hib }}$ deacylase activities. In each reaction, $2 \mu \mathrm{g}$ of core histones were incubated with 11 class I, II and IV deacetylases (HDAC1-HDAC11) at $37{ }^{\circ} \mathrm{C}$ for $12 \mathrm{~h}$. Reaction products were detected by western blot with indicated antibodies. (B) HDAC1 knockdown slightly affects global histone $\mathrm{K}_{\text {hib }}$ level in vivo. HEK293T cells were treated with siRNAs against HDAC1 for $48 \mathrm{~h}$ before being subjected to western blot analysis. The efficiency of siRNA knockdown was verified by western blot. (C) Western blot analysis showing that HDAC1 overexpression slightly affects global histone $\mathrm{K}_{\text {hib }}$ level in HEK293T cells. An empty vector PCDNA3.1 and a vector encoding PCDNA3.1-HA-HDAC1 were transfected into HEK293T cells for $48 \mathrm{~h}$ before being subjected to western blot analysis. (D) HDAC3 knockdown increases histone $\mathrm{K}_{\text {hib }}$ in vivo. U2OS cells were transfected twice with ON-TARGETplus SMARTpool siRNA for human HDAC3 (DHARMACON) for $24 \mathrm{~h}$. (E) HDAC2 knockout and HDAC2/HDAC3 double depletion increases histone $\mathrm{K}_{\text {hib }}$ in vivo. HEK293T cells were transfected with an empty vector PX458 and an HDAC2 knockout vector PX458-sgRNA (HDAC2) for $48 \mathrm{~h}$, respectively. Depletion of HDAC2 and HDAC3 was further achieved by using HDAC2 knockout HEK293T cell line transfected with siRNA mix against HDAC3. (F) Western blot analysis showing that HDAC2 and/ or HDAC3 overexpression decrease histone $\mathrm{K}_{\text {hib }}$ in HEK293T cells. An empty vector PCDNA3.1, a vector encoding PCDNA3.1-HA-HDAC2, a vector encoding PCDNA3.1-HA-HDAC3 and mixed vectors encoding PCDNA3.1-HA-HDAC2 and PCDNA3.1-HA-HDAC3 were transfected into HEK293T cells for $48 \mathrm{~h}$ before being subjected to western blot analysis. Coomassie staining of total histone was used as loading control. 
of lysine-acetylated proteins [22]. Given that cytoplasmic, mitochondrial and nuclear $\mathrm{K}_{\mathrm{ac}}$ can regulate various cellular processes, the $\mathrm{K}_{\text {hib }}$ pathway's major functions are likely widespread in diverse subcellular compartments.

\section{Functional annotation of the $K_{\text {hib }}$ proteome}

In order to explore the possible pathways affected by $\mathrm{K}_{\text {hib }}$, we performed a KEGG pathway enrichment analysis of the $\mathrm{K}_{\text {hib }}$ proteins [1]. Ribosome (adjusted $P=5.65$ $\times 10^{-35}$ ), spliceosome (adjusted $P=6.60 \times 10^{-25}$ ) and proteasome (adjusted $P=4.94 \times 10^{-13}$ ) pathways were most significantly enriched (Supplementary information, Data S2A). Notably, $66 \%, 48 \%$ and $57 \%$ of proteins in these pathways were 2-hydroxyisobutyrylated, respectively (Supplementary information, Data S2A). In addition, macromolecule transport-related pathways, such as RNA transport (adjusted $P=2.65 \times 10^{-10}$ ) and protein export (adjusted $P=2.28 \times 10^{-6}$ ) pathways, were also enriched (Supplementary information, Data S2A). Moreover, our data showed that $\mathrm{K}_{\text {hib }}$ proteins were enriched in energy metabolic networks, such as the citric cycle (adjusted $P$ $=2.28 \times 10^{-11}$ ), fatty acid metabolism (adjusted $P=1.24$ $\times 10^{-5}$ ) and pyruvate metabolism (adjusted $P=2.08 \times$ $10^{-5}$ ) (Supplementary information, Data S2A). Similar to the pathway analysis, unbiased gene ontology biological process and UniProt keywords annotation of the $\mathrm{K}_{\mathrm{hib}}$ proteome showed that $\mathrm{K}_{\text {hib }}$ proteins were associated with metabolic process and RNA processing (Supplementary information, Figure S6).

We also performed a protein complex enrichment analysis of the $\mathrm{K}_{\text {hib }}$ proteome with a manually curated CORUM database [41]. In accord with the pathway analysis, the top enriched protein complexes are associated with ribosome, spliceosome and proteasome (Supplementary information, Data S2B). In addition to these complexes, we identified significant enrichment of $\mathrm{K}_{\text {hib }}$ in the CCT micro-complex (adjusted $P=6.09 \times 10^{-10}$ ), the H2AX complex (adjusted $P=2.29 \times 10^{-8}$ ), the TNF- $\alpha /$

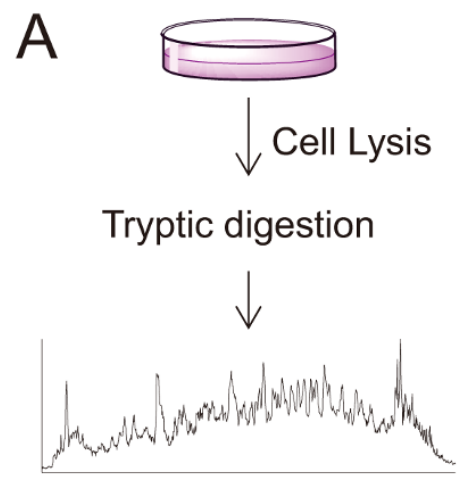

Peptides HPLC Separation
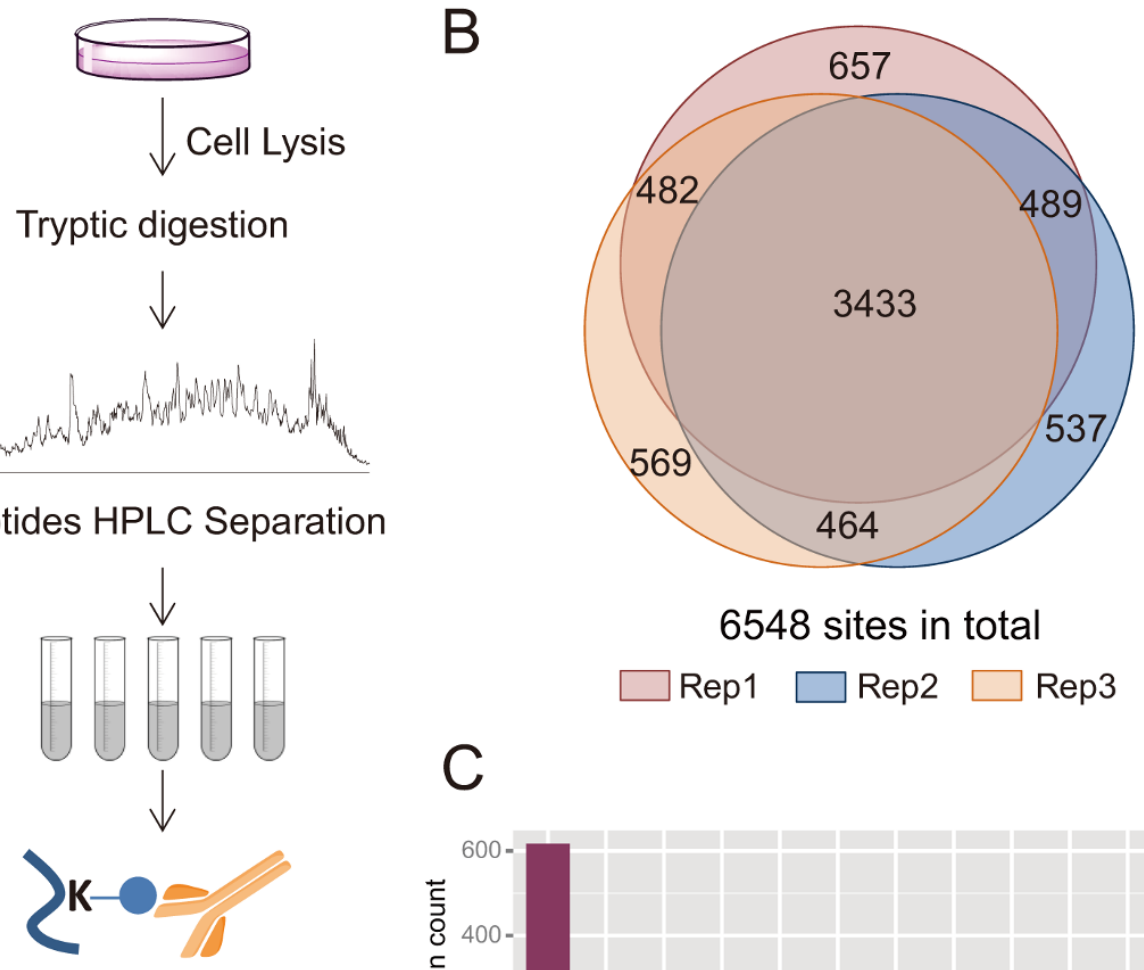

Immunoprecipitation
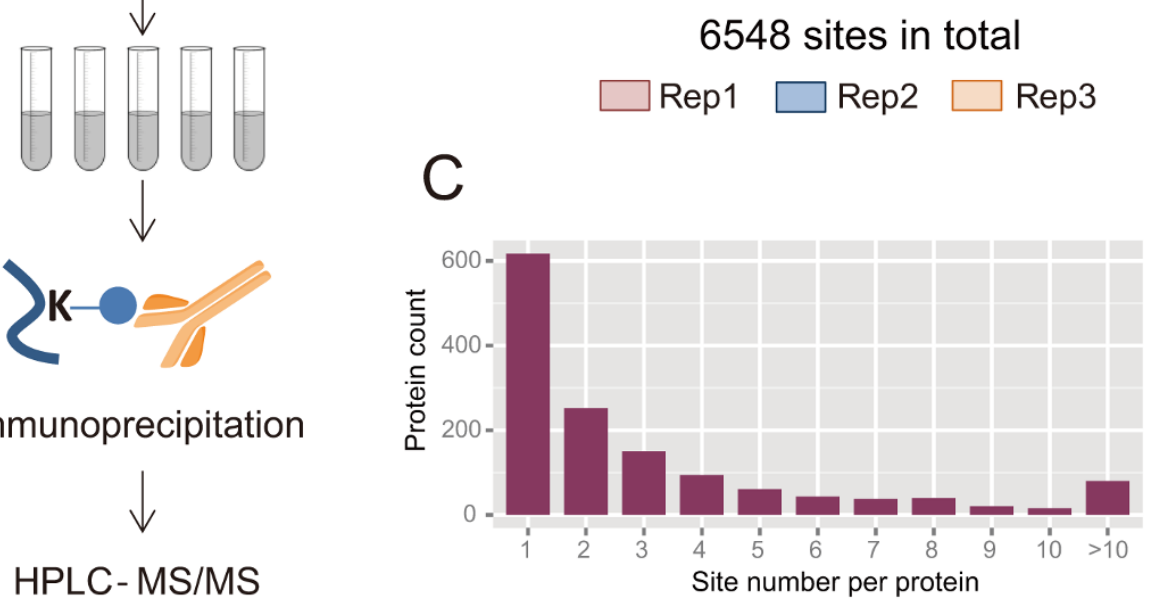

Figure 4 Systematic profiling of lysine 2-hydroxyisobutyrylation in HeLa cells. (A) Schematic overview of experimental workflow for the identification of $\mathrm{K}_{\text {hib }}$ in HeLa cells. (B) Pie chart shows experimental reproducibility of three biological replicates. (C) Distribution of the number of $\mathrm{K}_{\text {hib }}$ sites per protein. 
A

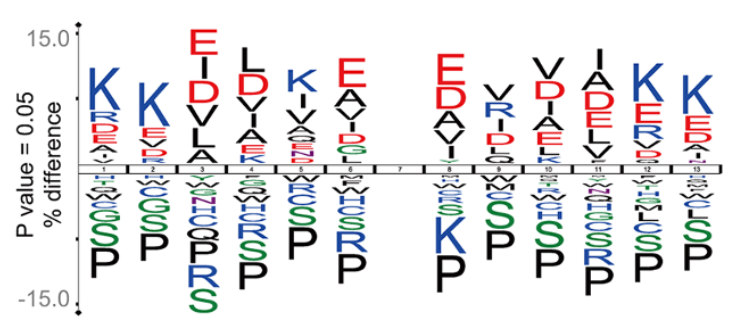

B

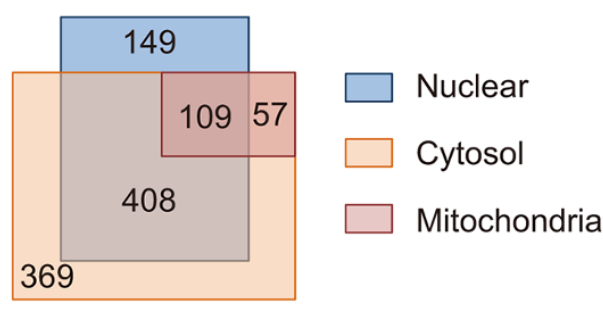

C

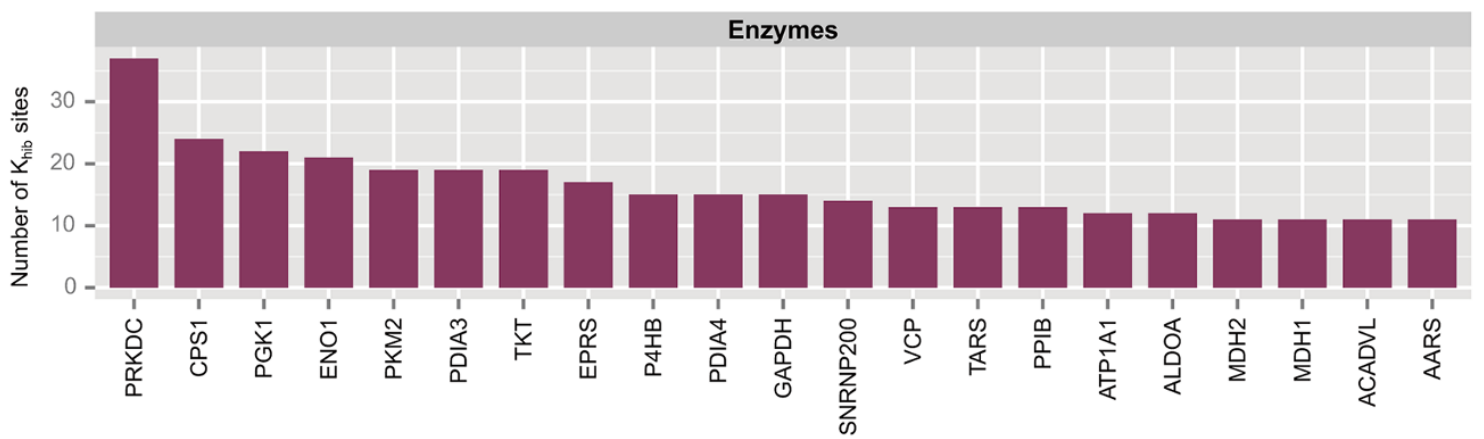

$\mathrm{D}$

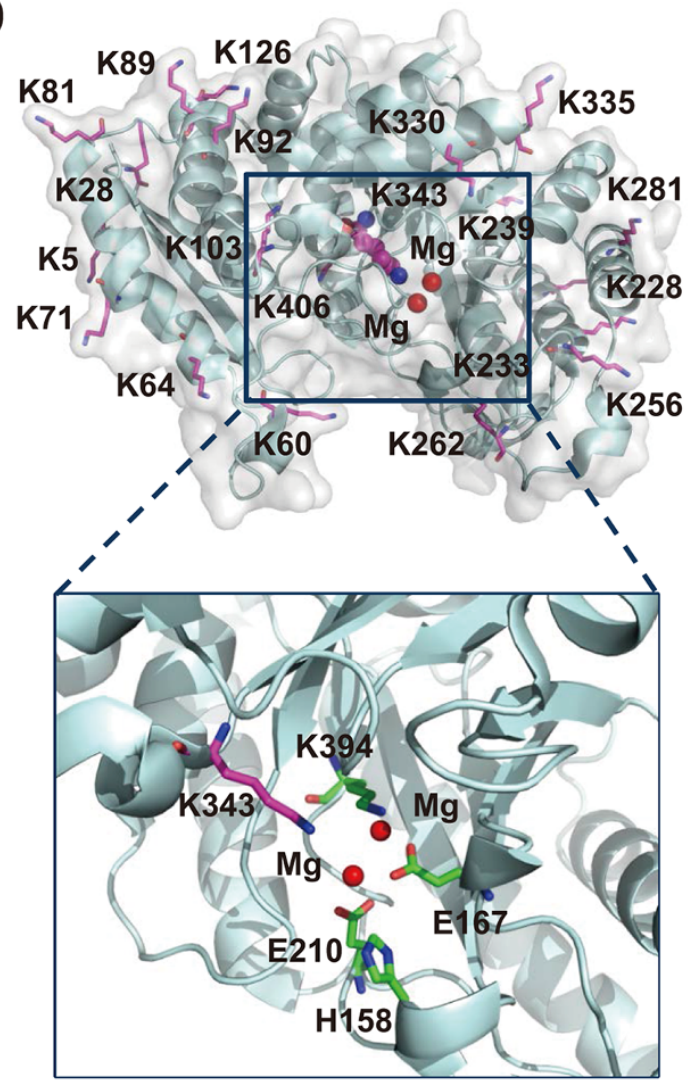

E

\begin{tabular}{l|l|l}
\hline Protein & Residue & Binding partner \\
\hline AHCY & K186 & Substrate \\
\hline ALDOA & K147 & Substrate \\
\hline CALR & K64 & Calcium \\
\hline DBI & K55 & Acyl-CoA \\
\hline EGFR & K745 & ATP \\
\hline FDPS & K123 & Isopentenyl diphosphate \\
\hline G6PD & K171 & Substrate \\
\hline GLUD1 & K147 & Substrate \\
\hline HADH & K127 & NAD \\
\hline HSDL2 & K42 & NADP \\
\hline HSP90AA2 K112 & ATP \\
\hline HSP90B1 & K168 & ATP \\
\hline PGK1 & K220 & ATP \\
\hline PTGR1 & K178 & NADP \\
\hline
\end{tabular}

Figure 5 Characterization of lysine 2-hydroxyisobutyrylation proteome in HeLa cells. (A) Consensus sequence logo shows a representative sequence for all $\mathrm{K}_{\text {hib }}$ sites. (B) Venn diagram shows cellular compartment distribution of 2-hydroxyisobutyrylated proteins. (C) Distribution of the number of $\mathrm{K}_{\text {hib }}$ sites on diverse enzymes. The enzymes with $<10 \mathrm{~K}_{\text {hib }}$ sites are not shown in this bar graph. (D) Three-dimensional structure of alpha-enolase (ENO1, PDB entry 2PSN) shown with $\mathrm{K}_{\text {hib }}$ sites. The important residues in the substrate binding pocked are shown in detail. (E) Table of the $\mathrm{K}_{\text {hib }}$ sites on key residues involving substrate or cofactor binding. 
NF- $\mathrm{BB}$ signal transduction pathway (adjusted $P=5.95$ $\times 10^{-8}$ ) and the DNA-PK-Ku-eIF2-NF90-NF45 complex (adjusted $P=6.44 \times 10^{-8}$ ) (Supplementary information, Data S2B). The TNF- $\alpha / \mathrm{NF}-\kappa \mathrm{B}$ signal transduction pathway plays a pivotal role in various biological processes, and dysregulation of this pathway is associated with many diseases [42]. Our data showed that 9 out of 14 subunits in this complex were 2-hydroxyisobutyrylated (Supplementary information, Data S2B). The DNAPK-Ku-eIF2-NF90-NF45 complex is involved in DNA double-strand break repair [43]. We found that $87.5 \%$ of proteins ( 7 out of 8 ) in this complex were 2-hydroxyisobutyrylated (Supplementary information, Data S2B). These results suggest that $\mathrm{K}_{\text {hib }}$ can be involved in diverse cellular functions and networks that include protein synthesis and degradation, cellular signaling and DNA repair.

$K_{\text {hib }}$ in enzymes

Of the 346 2-hydroxyisobutyrylated enzymes, 219 enzymes have multiple $K_{\text {hib }}$ sites. Of these, 21 enzymes were heavily modified and had more than $10 \mathrm{~K}_{\text {hib }}$ sites (Figure 5C; Supplementary information, Data S3). The DNA-dependent protein kinase catalytic subunit (PRKDC), the core component of the DNA-PK-Ku-eIF2NF90-NF45 complex, has $37 \mathrm{~K}_{\text {hib }}$ sites (Figure 5C). Glycolysis is a catabolic process that converts glucose into pyruvate via 10 enzymatic steps [44]. Strikingly, 5 out of the 10 key enzymes required for glycolysis were heavily modified, including phosphoglycerate kinase 1 (PGK1), alpha-enolase (ENO1), pyruvate kinase isoform M2 (PKM2), glyceraldehyde-3-phosphate dehydrogenase (GAPDH) and fructose-bisphosphate aldolase A (ALDOA) (Figure 5C). ENO1 is a highly-conserved enzyme that coverts 2-phosphoglycerate to the high-energy intermediate phosphoenolpyruvate. Remarkably, its activity center residue, K343, was 2-hydroxyisobutyrylated (Figure 5D). Previous experiments showed that mutations on this site (Lys to Ala or Met) abolished enzyme activity [45]. In addition, the crystal structure of ENO1 shows that two magnesium ions are located in the active pocked within $4 \AA$ to the epsilon nitrogen atom of K343 (Figure 5D), and both magnesium ions are thought to participate in the catalytic reaction [45]. Therefore, the K343 hib could not only inactivate the epsilon nitrogen atom, but is also likely to occupy the space of magnesium ions, thus disrupting the interaction network of the active-site residues and hampering enzymatic activity.

In addition to these enzyme active sites, we also found that many substrates or cofactor binding sites were 2-hydroxyisobutyrylated (Figure 5E). For example, K186 of adenosylhomocysteinase; K147 of ALDOA; K171 of glucose-6-phosphate 1-dehydrogenase; and K147 of glutamate dehydrogenase 1 are known to be important for substrate binding (www.uniprot.com). The K745 residue of epidermal growth factor receptor (EGFR), K112 of heat shock protein HSP 90-alpha A2, K168 of endoplasmin and $\mathrm{K} 220$ of PGK1 are critical residues for ATP binding (www.uniprot.com). $\mathrm{K}_{\text {hib }}$ on these positions is most likely to affect the protein functions by disrupting the binding interaction.

\section{Discussion}

Emerging evidence indicates that diverse newly-discovered lysine acylations are associated with normal cellular physiology and disease. Histone butyrylation, crotonylation and $\beta$-hydroxybutyrylation are associated with gene expression in diverse cellular systems [10, 46-48]. These modifications can also have specific "readers" to mediate their functions [49-52]. Lysine propionylation, butyrylation, malonylation, succinylation, glutarylation all contribute to multiple heritable genetic diseases [36, 40, 53-55]. These lines of evidence suggest that lysine acylations are a family of PTMs that are physiologically relevant.

Lysine acetylation not only occurs on core histones, but also on diverse other proteins in nuclei, cytosol and mitochondria, many of which are metabolic enzymes. Previous studies have suggested that the lysine acetylation pathway has diverse functions. Given the significant structural changes associated with $\mathrm{K}_{\text {hib }}$ and also its widespread abundance, its close association with gene expression, it seems that the $\mathrm{K}_{\text {hib }}$ pathway is also highly likely to function similar to lysine acetylation and to have diverse regulatory roles. However, study of the $\mathrm{K}_{\text {hib }}$ pathway is hindered by a lack of knowledge of its regulatory enzymes and key substrates, the major focus of this work.

Our findings on the $\mathrm{K}_{\text {hib }}$ activities of Esa1p/TIP60, HDAC 2 and HDAC3 broaden the enzymatic activities of the previously annotated HATs and HDACs. TIP60 is a cellular lysine acetyltransferase that is involved in the regulation of gene expression and DNA damage response. It exerts cellular functions principally through acetylation of histones and critical cellular proteins like p53, p21 and ATM kinase [56]. To our knowledge, TIP60 has not yet been found to have acyltransferase activity other than acetylation. Thus, many of the annotated acetylation-regulatory enzymes have an expanded repertoire of acyl-transferase activities, and our result provides additional complexity of enzymatic activities of these enzymes.

Our study of the comprehensive global lysine 2-hydroxyisobutyrylome has provided a data set of 6548 
reliable $\mathrm{K}_{\text {hib }}$ sites on 1725 proteins in HeLa cells. This data set represents the first $\mathrm{K}_{\text {hib }}$ proteome in mammalian cell to date, and illustrates the broad landscape of the $\mathrm{K}_{\text {hib }}$ pathway. Notably, $14 \mathrm{~K}_{\text {hib }}$ sites were located at substrate or cofactor-binding positions, suggesting $\mathrm{K}_{\text {hib }}$ on these positions may negatively regulate protein functions. Second, this study provides a valuable resource for understanding the molecular mechanism whereby $\mathrm{K}_{\mathrm{hib}}$ is associated with enzyme functions and human diseases. We detected $1252 \mathrm{~K}_{\text {hib }}$ sites on 346 enzymes in the HeLa $\mathrm{K}_{\text {hib }}$ proteome (Supplementary information, Data S3) and many of these enzymes are heavily 2-hydroxyisobutyrylated, suggesting important roles of $\mathrm{K}_{\text {hib }}$ in diverse cellular processes and development of disease. Third, our further analysis of the $\mathrm{K}_{\text {hib }}$ proteome has shed additional light on the crosstalk between $\mathrm{K}_{\mathrm{hib}}$ and phosphorylation. We identified $115 \mathrm{~K}_{\text {hib }}$ sites in the HeLa $\mathrm{K}_{\text {hib }}$ proteome located within five residues of reported phosphorylation sites (Supplementary information, Data S4) by mapping the $\mathrm{K}_{\text {hib }}$ proteome against the phosphorylome in UniProt database. Given that phosphorylation can serve as a functional on/off switch, these data suggest potential roles for $\mathrm{K}_{\text {hib }}$ in tuning protein functions through interplay with nearby phosphorylation sites.

Our study also sheds new light on the ways that microbial metabolites might affect human health and disease. The human gut harbors trillions of microorganisms that produce multiple metabolites, which have been demonstrated to play important roles in the development of diverse diseases [8]. For example, high levels of 2-hydroxyisobutyrate in the urine of obese people have been found associated with reduced bacterial diversity in "obese" gut microbiota [12]. However, the underlying mechanisms of how the microbial metabolites affect human health and disease are poorly understood. Emerging evidence has demonstrated that fluctuations in the availability of short-chain fatty acids could directly impinge on levels of their corresponding PTMs [10, 53, 57]. In this context, given the potentially important roles of $\mathrm{K}_{\text {hib }}$ in various cellular processes revealed in this study, it is highly likely that microbial metabolites, including 2-hydroxyisotutarate, play a regulatory role at the level of PTMs such as $\mathrm{K}_{\text {hib }}$ in a variety of host tissues and can ultimately affect host protein functions and the overall phenotype.

Identification of key regulatory elements for the $\mathrm{K}_{\text {hib }}$ pathway, including enzymes and substrate proteins, will mark a key step forward toward description of this pathway. It is expected that histone $\mathrm{K}_{\text {hib }}$ pathway will have unique binding modules in a similar fashion to histone lysine acetylation and crotonylation $[49,50]$. It seems highly likely that the relative abundance of histone $\mathrm{K}_{\mathrm{ac}}$ and $\mathrm{K}_{\text {hib }}$ in a given substrate protein such as a histone protein is regulated by metabolic status and concentrations of acyl-CoAs in a similar fashion as histone lysine crotonylation [10]. We now require functional studies of these enzymes and substrates, together with the discovery and characterization of their binding proteins (or "readers"), and investigations of the governing principles that acyl-CoA metabolism might have on these proteins. Such future studies will greatly enhance our understanding of the $\mathrm{K}_{\text {hib }}$ pathway and molecular regulation of cellular functions mediated by its cognate short-chain fatty acid.

\section{Materials and Methods}

\section{Plasmids, siRNA, antibodies and cell lines}

Tip60 was cloned into pcDNA3.0 with a Flag tag. The construction was verified by DNA sequencing. siRNA was purchased from Dharmacon (L-006301-00-0005). The antibodies used here were anti-Pan $\mathrm{K}_{\mathrm{ac}}$ (PTM Biolabs, PTM-101), anti-Pan $\mathrm{K}_{\text {hib }}$ (PTM Biolabs, PTM-801), anti-H4K8 $8_{\text {ac }}$ (PTM Biolabs, PTM-120), anti-H4K $8_{\text {hib }}$ (PTM Biolabs, PTM-805), anti-H4 (Abcam, ab31830), anti-Flag (Sigma-Aldrich, F7425), anti-Tubulin (Abcam, ab6160) and anti-Tip60 (Abcam, 23886). Cell lines were purchased from ATCC (www.atcc.org) and used without further authentication, including HEK293 (ATCC CRL-1573), HEK293T (ATCC CRL3216), HeLa (ATCC CCL-2) and U2OS (ATCC HTB-96). No mycoplasma contamination was detected using a MycoAlert Mycoplasma Detection Kit (Lonza, LT07-118).

\section{Stable isotope labeling of cells and transfections}

HEK293T cells were grown in lysine-free DMEM supplemented with $10 \%$ dialyzed FBS, and either light $\left({ }^{12} \mathrm{C}_{6}{ }^{14} \mathrm{~N}_{2}\right.$-L-Lysine $)$ or heavy $\left({ }^{13} \mathrm{C}_{6}{ }^{14} \mathrm{~N}_{2}\right.$-L-Lysine) lysine $(100 \mathrm{mg} / \mathrm{L})$. Cells were grown for more than seven generations to achieve more than $98 \%$ labeling efficiency. For the transfections, HeLa and HEK293 cells were cultured in DMEM medium supplemented with 10\% FBS, $50 \mathrm{U} /$ $\mathrm{mL}$ penicillin and $50 \mathrm{mg} / \mathrm{mL}$ streptomycin in a $5 \% \mathrm{CO}_{2}$ atmosphere at $37{ }^{\circ} \mathrm{C}$. Transfection to achieve transient overexpression was performed with Lipofectamine 2000 (Invitrogen) according to the manufacturer's instructions. siRNA transfection was performed with Lipofectamine RNAiMAX (Invitrogen) according to manufacturer's instructions. For HDAC1, HDAC2 and HDAC3 overexpression, five pools of HEK293T cells were transfected with an empty vector PCDNA3.1, a vector encoding PCDNA3.1HA-HDAC1, a vector encoding PCDNA3.1-HA-HDAC2, a vector encoding PCDNA3.1-HA-HDAC3 and mixed vectors encoding PCDNA3.1-HA-HDAC2 and PCDNA3.1-HA-HDAC3 for $48 \mathrm{~h}$.

\section{Depletion of HDAC1, HDAC2 and HDAC3}

Two pools of HEK293T cells were transfected twice with HDAC 1 siRNA (Genepharma, siHDAC1: (\#1) 5'-GCUCCUCUGACAAACGAAUTT-3'; (\#2) 5'-CCGGUCAUGUCCAAAGUAATT-3'; (\#3) 5'-GCUGUACAUUGACAUUGAUTT-3') and a negative control siRNA (Genepharma, 5'-UUCUCCGAACGUGUCACGUTT-3'), respectively. About $48 \mathrm{~h}$ after the second transfection, the cell lysates were probed with anti- $\mathrm{K}_{\mathrm{ac}}$ and anti- $\mathrm{K}_{\text {hib }}$ 
antibodies.

HEK293T cells were transfected with an empty vector PX458 and an HDAC2 knockout vector PX458-sgRNA (HDAC2), respectively, to get two stable cell lines. Depletion of HDAC2 and HDAC3 was further achieved by using the HDAC2 knockout HEK293T cell line transfected twice with a siRNA mix against HDAC3 (Genepharma, siHDAC3: (\#1) 5'-CCGCCAGACAAUCUUUGAATT-3'; (\#2) 5'-GAGCUUCCCUAUAGUGAAUTT-3'; (\#3) 5'-GGGAAUGCGUUGAAUAUGUTT-3'). The HDAC2 knockout HEK293T cells transfected twice with siRNA (Genepharma, 5'-UUCUCCGAACGUGUCACGUTT-3') were used as negative control. About $48 \mathrm{~h}$ after the last transfection, the $\mathrm{K}_{\mathrm{hib}}$ and $\mathrm{K}_{\mathrm{ac}}$ levels were assessed by western blot using extractions of whole-cell lysates.

\section{Preparation of cell lysate}

Cells were sonicated for $3 \mathrm{~min}$ on ice using a high-intensity ultrasonic processor (Scientz) in lysis buffer ( $8 \mathrm{M}$ urea, $2 \mathrm{mM}$ EDTA, $3 \mu \mathrm{M}$ TSA, $50 \mathrm{mM}$ NAM, $5 \mathrm{mM}$ DTT and 1\% Protease Inhibitor Cocktail III). The remaining debris was removed by centrifugation at $18000 \times \mathrm{g}$ at $4{ }^{\circ} \mathrm{C}$ for $3 \mathrm{~min}$. The protein concentration was determined using a 2-D Quant kit according to the manufacturer's instructions.

\section{Trypsin digestion of cell lysate}

Proteins in the cell lysate were reduced with $10 \mathrm{mM}$ DTT for $1 \mathrm{~h}$ at $37{ }^{\circ} \mathrm{C}$, alkylated with $20 \mathrm{mM}$ iodoacetamide for $45 \mathrm{~min}$ at room temperature in darkness, and the excess iodoacetamide was blocked by $20 \mathrm{mM}$ cysteine. Then the protein sample was diluted by adding $100 \mathrm{mM} \mathrm{NH}_{4} \mathrm{HCO}_{3}$ to reduce the urea concentration to $<2 \mathrm{M}$. Trypsin was added at 1:50 trypsin-to-protein mass ratio for the first digestion overnight and 1:100 trypsin-to-protein mass ratio for a second 4 h-digestion. Finally, $18 \mathrm{mg}$ of proteins from the HeLa cells lysate was digested for subsequent experiments.

\section{Peptide fractionation with high-pH reverse-phase chroma- tography}

The peptides from HeLa cells lysate were then divided into three equal parts, and each of them $(6 \mathrm{mg})$ was fractionated into six fractions by high $\mathrm{pH}$ reverse-phase HPLC using an Agilent 300 Extend C18 column ( $5 \mu \mathrm{m}$ particles, $4.6 \mathrm{~mm}$ ID, $250 \mathrm{~mm}$ length). Briefly, peptides were first separated using a gradient of $2 \%-60 \%$ acetonitrile in $10 \mathrm{mM}$ ammonium bicarbonate at $\mathrm{pH} 10$ over 90 min into 90 fractions. The peptides were then combined into six fractions and dried by vacuum centrifugation.

\section{Immunoaffinity enrichment}

To enrich $\mathrm{K}_{\text {hib }}$ peptides, total peptides dissolved in NETN buffer $(100 \mathrm{mM} \mathrm{NaCl}, 1 \mathrm{mM}$ EDTA, $50 \mathrm{mM}$ Tris-HCl, 0.5\% NP-40, $\mathrm{pH}$ 8.0) were incubated with pre-washed pan anti- $\mathrm{K}_{\text {hib }}$ beads (PTM Biolabs Inc., Chicago, IL) at $4{ }^{\circ} \mathrm{C}$ overnight with gentle shaking. The beads were washed four times with NETN buffer and twice with $\mathrm{ddH}_{2} \mathrm{O}$. The bound peptides were eluted from the beads with $0.1 \%$ trifluoroacetic acid, and the eluted fractions were combined and vacuum-dried.

\section{Mass spectrometry}

Samples were dissolved in $0.1 \%$ formic acid and loaded onto a reversed-phase pre-column (Acclaim PepMap 100, Thermo Scientific). Peptide separation was performed using a reversed-phase analytical column (Acclaim PepMap RSLC, Thermo Scientific) with a gradient of $5-80 \%$ HPLC buffer B $(0.1 \%$ formic acid in $90 \%$ acetonitrile, $\mathrm{v} / \mathrm{v})$ in buffer $\mathrm{A}(0.1 \%$ formic acid in water, $\mathrm{v} / \mathrm{v})$ at a flow rate of $300 \mathrm{nl} / \mathrm{min}$ over $60 \mathrm{~min}$ on an EASY-nLC 1000 UPLC system. The samples were analyzed by Q Exactive Plus Mass Spectrometers (ThermoFisher Scientific). A data-dependent procedure that alternated between one full mass scan followed by the top 20 most intense precursor ions was applied with $30 \mathrm{~s} \mathrm{dy-}$ namic exclusion. Intact peptides were detected with a resolution of 70000 at $200 \mathrm{~m} / \mathrm{z}$, and ion fragments were detected with a resolution of 17500 at $28 \%$ normalized collision energy.

\section{Database search and data filter criteria}

The resulting MS/MS data were processed using MaxQuant with integrated Andromeda search engine (v.1.3.0.5) [58]. Tandem mass spectra were searched against the UniProt Human protein database (88 277 entries, http://www.uniprot.org) concatenated with reverse decoy database. Trypsin/P was specified as cleavage enzyme allowing up to two missing cleavages and five modifications per peptide. Carbamidomethylation on cysteine was specified as fixed modification. Oxidation on methionine, 2-hydroxyisobutyrylation on lysine, acetylation on lysine and acetylation on protein $\mathrm{N}$-terminus were specified as variable modifications. False discovery rate thresholds for protein, peptide and modification site were specified at $1 \%$. Minimum peptide length was set at 7 . All the other parameters in MaxQuant were set to default values. $\mathrm{K}_{\mathrm{hib}}$ identified on peptides from reverse or contaminant protein sequences, peptides with an Andromeda score below 40, site localization probability below 0.75 and redundant $\mathrm{K}_{\text {hib }}$ sites were removed. In addition, $\mathrm{K}_{\text {hib }}$ sites on the peptide $\mathrm{C}$-terminus were eliminated, unless the peptide $\mathrm{C}$-terminus was also the corresponding protein $\mathrm{C}$-terminus. For the SILAC sample data, $\mathrm{K}_{\text {hib }}$ site ratios were normalized by the quantified protein expression levels.

\section{In vitro acetylation and 2-hydroxyisobutyrylation assay}

Recombinant human Tip60 and Histone H4 proteins were purchased from Cayman (10783) and NEB (M2504S), respectively. For each reaction, $250 \mathrm{ng}$ of Tip60 protein, $2.5 \mu \mathrm{g}$ of $\mathrm{H} 4$ protein and $10 \mu \mathrm{M}$ of CoA were added in reaction buffer $(50 \mathrm{mM}$ Tris-CI, pH 8.0, 10\% glycerol, $10 \mathrm{mM}$ butyric acid, $0.1 \mathrm{mM}$ EDTA, $1 \mathrm{mM}$ DTT and $1 \mathrm{mM}$ PMSF). The reaction mixtures were incubated at $30{ }^{\circ} \mathrm{C}$ for $1 \mathrm{~h}$, followed by addition of SDS sample buffer. The levels of acetylation and 2-hydroxyisobutyrylation were assessed by western blot.

\section{PicNuA4 in vitro assay}

The NCP with 147 bp 601 "wisdom" sequence was prepared using luger's protocol. PicNuA4 complex was prepared using an unpublished method. The reaction system was $1 \mu \mathrm{M}$ NCP, 0.01 $\mu \mathrm{M}$ picNuA4, $50 \mu \mathrm{M}$ 2-hib-CoA, $50 \mathrm{mM} \mathrm{NaCl}, 10 \mathrm{mM}$ HEPES ( $\mathrm{pH} 7.0), 0.1 \mathrm{mg} / \mathrm{mL}$ BSA. The assay was performed at room temperature, utilizing picNuA4 to start the reactions with a time-based gradient. SDS-loading buffer was used to stop the reactions with incubation at $100{ }^{\circ} \mathrm{C}$ for $1 \mathrm{~min}$. The signal was detected by western blot.

\section{Protein function annotation analysis}

Enrichment analysis for KEGG pathway and PFAM domain was performed using a hypergeometric test in GOstats package in $\mathrm{R}$ [59]. Protein complexes were enriched basing on that manually 
curated CORUM protein complex database [41] for all mammals using a hypergeometric test. Unbiased gene ontology terms and UniProt keywords enrichment analyses were performed using a web tool (https://agotool.sund.ku.dk) [60].

\section{Protein-protein interaction network analysis}

The STRING database (v10, http://www.string-db.org/) was used for analyzing the protein-protein interaction network of the Tip60-regulated $\mathrm{K}_{\text {hib }}$ proteome. Interactions with the highest confidence score (above 0.9) were selected and the network was visualized in Cytoscape (v.3.2.1).

\section{Correlation between $K_{\text {hib }}$ and mutation/phosphorylation}

In-house developed scripts were applied to map $\mathrm{K}_{\text {hib }}$ to known mutations and phosphorylation sites. Disease-related mutations were extracted from UniProt (http://www.uniprot.org) and COSMIC (Catalogue of Somatic Mutations in Cancer, http://cancer. sanger.ac.uk/cosmic) databases. Protein dysfunction-related mutations, substrate/cofactor-binding sites and reported phosphorylation sites were extracted from UniProt database.

\section{Chemical synthesis of 2-hydroxyisobutyryl-CoA}

The method used to synthesize 2-hydroxyisobutyryl-CoA was modified from a previous study [61]. About $0.88 \mathrm{~g}(10 \mathrm{mmol})$ 2-hydroxyisobutyric acid and $1 \mathrm{~mL}$ thiophenol were dissolved in $50 \mathrm{~mL}$ pre-cooled dimethylformamide (DMF), to which $2.52 \mathrm{~g}$ (12.2 mmol) dicyclohexylcarbodiimide in $50 \mathrm{~mL}$ DMF was added drop by drop and the mixture was stirred for $3 \mathrm{~h}$ on ice bath. About $40 \mathrm{~mL}$ of cold water was then added and the solution was filtered. The filtrate was extracted with $100 \mathrm{~mL}$ of ether and the organic layer was washed three times with saturated $\mathrm{NaCl}$. The ether extract was dried using anhydrous sodium sulfate and ether evaporated. The residue was then purified by silica gel column chromatography with an elution solvent consisting of ethylacetate:hexane (20:1). The roughly purified product was further purified by silica thin-layer chromatography with an elution solvent consisting of ethylacetate:hexane (1:4). The target band was collected and the purified S-phenyl 2-hydroxy-2-methylpropanethioate was used as the reactant for the next step. $16 \mathrm{mg}$ of S-phenyl 2-hydroxy-2-methylpropanethioate was dissolved in $500 \mu \mathrm{L} 0.1$ $\mathrm{M} \mathrm{NaHCO}_{3}(\mathrm{pH} \mathrm{8.0)}$ and $200 \mu \mathrm{L}$ dioxane mixture was added to a solution of $10 \mathrm{mg}$ sodium salt of CoA dissolved in $1 \mathrm{~mL} \mathrm{NaHCO}_{3}$ (pH 8.0) at $0{ }^{\circ} \mathrm{C}$. The mixture was reacted overnight, and then was neutralized by adding $1 \mathrm{~N} \mathrm{HCl}$ to $\mathrm{pH} 7.0$ to stop the reaction. About $8 \mathrm{~mL}$ ether was used to extract the unreacted reactant and this step was repeated five times. Then $8 \mathrm{~mL}$ of ethylacetate was used to extract the water phase and this step was repeated eight times. The final product remained in the water phase. Water was allowed to evaporate at $30{ }^{\circ} \mathrm{C}$ in order to achieve the solid end product.

\section{Data availability}

The mass spectrometry proteomics data have been deposited in the ProteomeXchange Consortium via the PRIDE [62] partner repository with the data set identifier PXD005414.

\section{Acknowledgments}

Our work was supported by the National Institutes of Health
(NIH) award GM105933, DK107868 and GM115961 (YZ). This work was also supported by the National Key Research and Development Program of China (2017YFA0505103 to JD), Research Fund for the Doctoral Program of Higher Education of China (20120002110022 to JD) and the National Natural Science Foundation of China (81570060 to LD).

\section{Author Contributions}

$\mathrm{YZ}$ and JD designed and coordinated the whole project. HH performed the proteomics experiments, data analysis and bioinformatics analysis, and helped coordinate the project. SQ performed the immunoprecipitation and Tip60-related experiments. JH and ZL were involved in yeast acyltransferases assay and verification experiments. XW, LG, WZ, LD and WG were involved in the HDAC assay and verification experiments. PX and ZC performed the modeling experiments. FL and JW synthesized 2-hydroxyisobutyryl-CoA. HH, YZ and JD wrote the manuscript. All authors discussed the results and commented on the manuscript.

\section{Competing Financial Interests}

$\mathrm{YZ}$ is on the science advisory board of PTM Biolabs.

\section{References}

1 Kanehisa M, Goto S. KEGG: kyoto encyclopedia of genes and genomes. Nucleic Acids Res 2000; 28:27-30.

2 Fierz B, Muir TW. Chromatin as an expansive canvas for chemical biology. Nat Chem Biol 2012; 8:417-427.

3 Walsh CT, Garneau-Tsodikova S, Gatto GJ Jr. Protein posttranslational modifications: the chemistry of proteome diversifications. Angew Chem Int Ed Engl 2005; 44:7342-7372.

4 DeBerardinis RJ, Thompson CB. Cellular metabolism and disease: what do metabolic outliers teach us? Cell 2012; 148:1132-1144.

5 Moellering RE, Cravatt BF. Functional lysine modification by an intrinsically reactive primary glycolytic metabolite. Science 2013; 341:549-553.

6 Koh A, De Vadder F, Kovatcheva-Datchary P, Backhed F. From dietary fiber to host physiology: short-chain fatty acids as key bacterial metabolites. Cell 2016; 165:1332-1345.

7 Russell WR, Hoyles L, Flint HJ, Dumas ME. Colonic bacterial metabolites and human health. Curr Opin Microbiol 2013; 16:246-254.

8 Lee WJ, Hase K. Gut microbiota-generated metabolites in animal health and disease. Nat Chem Biol 2014; 10:416-424.

9 den Besten G, van Eunen K, Groen AK, Venema K, Reijngoud DJ, Bakker BM. The role of short-chain fatty acids in the interplay between diet, gut microbiota, and host energy metabolism. J Lipid Res 2013; 54:2325-2340.

10 Sabari BR, Tang Z, Huang H, et al. Intracellular crotonyl-CoA stimulates transcription through p300-catalyzed histone crotonylation. Mol Cell 2015; 58:203-215.

11 Sabari BR, Zhang D, Allis CD, Zhao YM. Metabolic regulation of gene expression through histone acylations. Nat Rev Mol Cell Biol 2017; 18:90-101.

12 Calvani R, Miccheli A, Capuani G, et al. Gut microbiome-derived metabolites characterize a peculiar obese urinary metabotype. Int J Obes 2010; 34:1095-1098.

13 Li M, Wang B, Zhang M, et al. Symbiotic gut microbes mod- 
ulate human metabolic phenotypes. Proc Natl Acad Sci USA 2008; 105:2117-2122.

14 Koppel N, Balskus EP. Exploring and understanding the biochemical diversity of the human microbiota. Cell Chem Biol 2016; 23:18-30.

15 Dai L, Peng C, Montellier E, et al. Lysine 2-hydroxyisobutyrylation is a widely distributed active histone mark. Nat Chem Biol 2014; 10:365-370.

16 Allfrey VG, Faulkner R, Mirsky AE. Acetylation and methylation of histones and their possible role in the regulation of RNA synthesis. Proc Natl Acad Sci USA 1964; 51:786-794.

17 Allis CD, Glover CV, Bowen JK, Gorovsky MA. Histone variants specific to the transcriptionally active, amitotically dividing macronucleus of the unicellular eucaryote, Tetrahymena thermophila. Cell 1980; 20:609-617.

18 Brownell JE, Zhou J, Ranalli T, et al. Tetrahymena histone acetyltransferase A: a homolog to yeast Gen5p linking histone acetylation to gene activation. Cell 1996; 84:843-851.

19 Brownell JE, Allis CD. An activity gel assay detects a single, catalytically active histone acetyltransferase subunit in Tetrahymena macronuclei. Proc Natl Acad Sci USA 1995; 92:63646368.

$20 \mathrm{Gu}$ W, Shi XL, Roeder RG. Synergistic activation of transcription by CBP and p53. Nature 1997; 387:819-823.

21 Kim SC, Sprung R, Chen Y, et al. Substrate and functional diversity of lysine acetylation revealed by a proteomics survey. Mol Cell 2006; 23:607-618.

22 Choudhary C, Kumar C, Gnad F, et al. Lysine acetylation targets protein complexes and co-regulates major cellular functions. Science 2009; 325:834-840.

23 Zhao S, Xu W, Jiang W, et al. Regulation of cellular metabolism by protein lysine acetylation. Science 2010; 327:10001004.

24 Chen Y, Zhao W, Yang JS, et al. Quantitative acetylome analysis reveals the roles of SIRT1 in regulating diverse substrates and cellular pathways. Mol Cell Proteomics 2012; 11:10481062.

25 Sapountzi V, Logan IR, Robson CN. Cellular functions of TIP60. Int J Biochem Cell Biol 2006; 38:1496-1509.

26 Chen Y, Sprung R, Tang Y, et al. Lysine propionylation and butyrylation are novel post-translational modifications in histones. Mol Cell Proteomics 2007; 6:812-819.

27 Allard S, Utley RT, Savard J, et al. NuA4, an essential transcription adaptor/histone $\mathrm{H} 4$ acetyltransferase complex containing Esalp and the ATM-related cofactor Tralp. EMBO J 1999; 18:5108-5119.

28 Boudreault AA, Cronier D, Selleck W, et al. Yeast enhancer of polycomb defines global Esa1-dependent acetylation of chromatin. Genes Dev 2003; 17:1415-1428.

$29 \mathrm{Xu} \mathrm{P}, \mathrm{Li} \mathrm{CM}$, Chen $\mathrm{ZH}$, et al. The NuA4 core complex acetylates nucleosomal histone $\mathrm{H} 4$ through a double recognition mechanism. Mol Cell 2016; 63:965-975.

30 Mitchell L, Lambert JP, Gerdes M, et al. Functional dissection of the NuA4 histone acetyltransferase reveals its role as a genetic hub and that Eaf1 is essential for complex integrity. Mol Cell Biol 2008; 28:2244-2256.

31 Smith ER, Eisen A, Gu WG, et al. ESA1 is a histone acetyltransferase that is essential for growth in yeast. Proc Natl Acad Sci USA 1998; 95:3561-3565.
32 Gao C, Bourke E, Scobie M, et al. Rational design and validation of a Tip60 histone acetyltransferase inhibitor. Sci Rep 2014; 4:5372.

33 Peng C, Lu Z, Xie Z, et al. The first identification of lysine malonylation substrates and its regulatory enzyme. Mol Cell Proteomics 2011; 10:M111.012658.

34 Du J, Zhou Y, Su X, et al. Sirt5 is a NAD-dependent protein lysine demalonylase and desuccinylase. Science 2011; 334:806-809.

35 Jiang H, Khan S, Wang Y, et al. SIRT6 regulates TNF-alpha secretion through hydrolysis of long-chain fatty acyl lysine. Nature 2013; 496:110-113.

36 Park J, Chen Y, Tishkoff DX, et al. SIRT5-mediated lysine desuccinylation impacts diverse metabolic pathways. Mol Cell 2013; 50:919-930.

37 Rardin MJ, He W, Nishida Y, et al. SIRT5 regulates the mitochondrial lysine succinylome and metabolic networks. Cell Metab 2013; 18:920-933.

38 Nishida Y, Rardin MJ, Carrico C, et al. SIRT5 regulates both cytosolic and mitochondrial protein malonylation with glycolysis as a major target. Mol Cell 2015; 59:321-332.

39 Svinkina T, Gu HB, Silva JC, et al. Deep, quantitative coverage of the lysine acetylome using novel anti-acetyl-lysine antibodies and an optimized proteomic workflow. Mol Cell Proteomics 2015; 14:2429-2440.

40 Colak G, Pougovkina O, Dai L, et al. Proteomic and biochemical studies of lysine malonylation suggest its malonic aciduria-associated regulatory role in mitochondrial function and fatty acid oxidation. Mol Cell Proteomics 2015; 14:30563071.

41 Ruepp A, Waegele B, Lechner M, et al. CORUM: the comprehensive resource of mammalian protein complexes--2009. Nucleic Acids Res 2010; 38:D497-501.

42 Bouwmeester T, Bauch A, Ruffner H, et al. A physical and functional map of the human TNF-alpha/NF-kappa B signal transduction pathway. Nat Cell Biol 2004; 6:97-105.

43 Ting NS, Kao PN, Chan DW, Lintott LG, Lees-Miller SP. DNA-dependent protein kinase interacts with antigen receptor response element binding proteins NF90 and NF45. J Biol Chem 1998; 273:2136-2145.

44 Lunt SY, Vander Heiden MG. Aerobic glycolysis: meeting the metabolic requirements of cell proliferation. Annu Rev Cell Dev Biol 2011; 27:441-464.

45 Pancholi V. Multifunctional alpha-enolase: its role in diseases. Cell Mol Life Sci 2001; 58:902-920.

46 Goudarzi A, Zhang D, Huang H, et al. Dynamic competing histone $\mathrm{H} 4 \mathrm{~K} 5 \mathrm{~K} 8$ acetylation and butyrylation are hallmarks of highly active gene promoters. Mol Cell 2016; 62:169-180.

47 Xie Z, Zhang D, Chung D, et al. Metabolic regulation of gene expression by histone lysine beta-hydroxybutyrylation. Mol Cell 2016; 62:194-206.

48 Tan M, Luo H, Lee S, et al. Identification of 67 histone marks and histone lysine crotonylation as a new type of histone modification. Cell 2011; 146:1016-1028.

49 Li YY, Sabari BR, Panchenko T, et al. Molecular coupling of histone crotonylation and active transcription by AF9 YEATS domain. Mol Cell 2016; 62:181-193.

50 Zhao D, Guan HP, Zhao S, et al. YEATS2 is a selective histone crotonylation reader. Cell Res 2016; 26:629-632. 
51 Andrews FH, Shinsky SA, Shanle EK, et al. The Taf14 YEATS domain is a reader of histone crotonylation. Nat Chem Biol 2016; 12:396-398.

52 Flynn EM, Huang OW, Poy F, et al. A subset of human bromodomains recognizes butyryllysine and crotonyllysine histone peptide modifications. Structure 2015; 23:1801-1814.

53 Hirschey MD, Zhao YM. Metabolic regulation by lysine malonylation, succinylation, and glutarylation. Mol Cell Proteomics 2015; 14:2308-2315.

54 Tan M, Peng C, Anderson KA, et al. Lysine glutarylation is a protein posttranslational modification regulated by SIRT5. Cell Metab 2014; 19:605-617.

55 Pougovkina O, Te Brinke H, Wanders RJ, Houten SM, de Boer VC. Aberrant protein acylation is a common observation in inborn errors of acyl-CoA metabolism. J Inherit Metab Dis 2014; 37:709-714.

56 Squatrito M, Gorrini C, Amati B. Tip60 in DNA damage response and growth control: many tricks in one HAT. Trends Cell Biol 2006; 16:433-442.
57 Sabari BR, Zhang D, Allis CD, Zhao Y. Metabolic regulation of gene express through histone acylations. Nat Rev Mol Cell Biol 2017; 18:90-101.

58 Cox J, Mann M. MaxQuant enables high peptide identification rates, individualized p.p.b.-range mass accuracies and proteome-wide protein quantification. Nat Biotechnol 2008; 26:1367-1372.

59 Falcon S, Gentleman R. Using GOstats to test gene lists for GO term association. Bioinformatics 2007; 23:257-258.

60 Scholz C, Lyon D, Refsgaard JC, Jensen LJ, Choudhary C, Weinert BT. Avoiding abundance bias in the functional annotation of post-translationally modified proteins. Nat Methods 2015; 12:1003-1004.

61 Padmakumar R, Gantla S, Banerjee R. A rapid method for the synthesis of methylmalonyl-coenzyme A and other CoA-esters. Anal Biochem 1993; 214:318-320.

62 Vizcaino JA, Csordas A, del-Toro N, et al. 2016 update of the PRIDE database and its related tools. Nucleic Acids Res 2016; 44:D447-D456.

(Supplementary information is linked to the online version of the paper on the Cell Research website.) 